\title{
PROCESSO METODOLÓGICO DE ELABORAÇÃO DE UMA CARTILHA EDUCATIVA SOCIOAMBIENTAL E SUAS POSSÍVEIS APLICAÇÕES NA SOCIEDADE
}

Raynon Joel Monteiro Alves ${ }^{1}$

Ana Lúcia Nunes Gutjahr ${ }^{2}$

Altem Nascimento Pontes ${ }^{3}$

Resumo: Este estudo teve por objetivo demonstrar o procedimento metodológico de elaboração de uma cartilha intitulada "Comunidades de Marapanim e o meio ambiente: uma relação (in)sustentável?", a qual foi resultado de uma pesquisa realizada em três povoados do município de Marapanim-PA, além das possíveis aplicações do material na sociedade. Tal cartilha apresenta 11 tópicos principais que discorrem sobre a caracterização socioeconômica e ambiental das comunidades, os problemas socioambientais, a importância de atividades educativas e as considerações finais. Esse material foi elaborado em linguagem simples e de fácil compreensão, a fim de alcançar o maior número possível de pessoas, em espaços formais e não formais de ensino. A referida cartilha consiste num instrumento viável de aproximação do conhecimento acadêmico-científico com a sociedade e um meio para sensibilizá-la sobre a problemática socioambiental e a possibilidade de nela intervir por meio de ações sustentáveis e de Educação Ambiental.

Palavras-chave: Educação Ambiental; Comunidades Rurais; Material Paradidático; Popularização da Ciência; Problemas Socioambientais.

1 Universidade Federal do Pará. E-mail: raynon_alves@yahoo.com.br

2 Universidade do Estado do Pará. E-mail: melcam@uol.com.br

3 Universidade do Estado do Pará. E-mail: altempontes@hotmail.com

Revbea, São Paulo, V. 14, № 2: 69-85, 2019.

revista brasileira

educação ambiental 


\section{Introdução}

Os problemas socioambientais contemporâneos vêm sendo ampliados pela superexploração dos recursos naturais, o que repercute em escala local e global, porém, diante disso, posiciona-se a Educação Ambiental (EA) como o processo que permite ao indivíduo e ao seu grupo social o questionamento acerca das questões ambientais (NUNES; SILVA; ARAÚJO, 2013) e de como mitigá-las por meio de ações sustentáveis. Desta forma, a EA permite a construção de valores sociais, conhecimentos, atitudes e competências voltadas para a conservação do meio ambiente, que é um bem de uso comum e necessário à sadia qualidade de vida da sociedade (BRASIL, 1999).

Dada a importância da EA como o processo que assegura a perenidade das ações de gestão ambiental por meio de mudanças de comportamentos e elevação da consciência ambiental das pessoas (BACELAR et al., 2009), no Brasil, a Lei № 9.795/1999 instituiu a EA e a caracterizou como um componente curricular, essencial e permanente, da educação nacional, podendo ser desenvolvida em caráter formal (em instituições públicas e privadas de ensino) e não formal. Este último corresponde às ações e práticas educativas voltadas à sensibilização de populações tradicionais, agricultores, sociedade em geral sobre as questões ambientais e à sua organização e participação na qualidade do meio ambiente (BRASIL, 1999).

Uma das possibilidades de se promover a EA no âmbito formal e não formal é a utilização de materiais paradidáticos que podem ser direcionados a várias pessoas da sociedade ou a um público de interesse. É neste sentido que se destaca também a chamada Popularização da Ciência, que é uma estratégia utilizada em dias atuais para transpor o conhecimento acadêmicocientífico de pesquisadores e cientistas (especialistas) para o público leigo (não especialista) (BUENO, 2010), a partir de uma linguagem e métodos de fácil compreensão.

Diante disso, a confecção de materiais de divulgação, como as cartilhas, visa tornar determinadas temáticas atrativas à população e vem contribuindo para o desenvolvimento científico e social (RABELO; GUTJAHR; HARADA, 2015). Tais cartilhas, em particular, podem ser elaboradas a partir de uma realidade estudada, associando elementos verbais e não verbais, como imagens e esquemas, a fim de facilitar a socialização e o entendimento de informações que precisam ser compartilhadas entre as pessoas.

Neste processo, a produção e divulgação de cartilhas educativas é uma forma viável de informar e sensibilizar as pessoas acerca de questões socioambientais que as acometem, tendo como base os resultados de pesquisas realizadas in loco em grupamentos humanos rurais. A exemplo disso, a dissertação do primeiro autor, intitulada: "Diagnóstico socioeconômico, ambiental e de sustentabilidade de comunidades rurais de Marapanim, Pará, Brasil", do Programa de Pós-graduação em Ciências Ambientais (PPGCA), da Universidade do Estado do Pará (UEPA), gerou para a sociedade uma cartilha 
paradidática denominada: "Comunidades de Marapanim e o meio ambiente: uma relação (in)sustentável?".

Diante do exposto, o objetivo do presente estudo foi demonstrar o procedimento metodológico de elaboração da referida cartilha como produto de pesquisa científica, assim como suas possíveis aplicações na sociedade, a fim de ressaltar a importância da difusão de conhecimentos acadêmico-científicos e de EA para a compreensão da realidade estudada e de ações para mitigar/prevenir alguns problemas socioambientais.

\section{Metodologia}

A cartilha foi elaborada considerando um estudo socioambiental realizado em três comunidades do município de Marapanim: Guarajubal, Porto Alegre e Cipoteua, situadas a $3 \mathrm{~km}, 8 \mathrm{~km}$ e $50 \mathrm{~km}$ da zona urbana do município, respectivamente, e que desenvolvem diferentes atividades agroextrativistas, como a captura e o beneficiamento manual do caranguejouçá (Ucides cordatus L. 1763) em Guarajubal; a pesca artesanal, em Porto Alegre, e a agricultura familiar, em Cipoteua. Estas comunidades foram selecionadas para o estudo por representarem a realidade dos povoados adjacentes.

Para a elaboração da cartilha, os dados oriundos do estudo realizado foram analisados qualitativamente e recorreu-se às pesquisas bibliográficas sobre o assunto para a proposição de ações mitigadoras ou preventivas para os problemas socioambientais encontrados nas comunidades. As ilustrações foram coletadas da internet (Google imagens) e em ambiente natural, com o uso de uma câmera digital. O referido material paradidático foi elaborado em estrutura esquemática e texto com linguagem simples para se tornar acessível a pessoas de qualquer faixa etária e nível escolar. Para a diagramação foi utilizado o Software Power Point 2016, com formatação em tamanho A4, fonte Arial Black, tamanho 25 no título de cada seção e Calibri, 20, no corpo do manuscrito.

Pressupondo-se a ampla difusão da cartilha aos moradores das comunidades estudadas; alunos da Educação Básica e Superior; Órgãos Públicos e Privados, principalmente os relacionados ao Poder Executivo Municipal; população em geral e demais interessados no assunto, realizou-se a doação da mídia (original em CD) a um representante da Prefeitura de Marapanim, durante o VI Simpósio de Estudos e Pesquisas em Ciências Ambientais, do PPGCA-UEPA, além da socialização desse material no Seminário e Primeira Audiência Pública do Plano Diretor Participativo do município. 


\section{Resultados e discussão}

O material contém uma capa, que destaca o título da cartilha, os autores e uma imagem que representa uma das realidades de Marapanim (a pesca artesanal); e uma contracapa, que contém as logomarcas das instituições que colaboraram com a realização da pesquisa/dissertação (Figura 1).

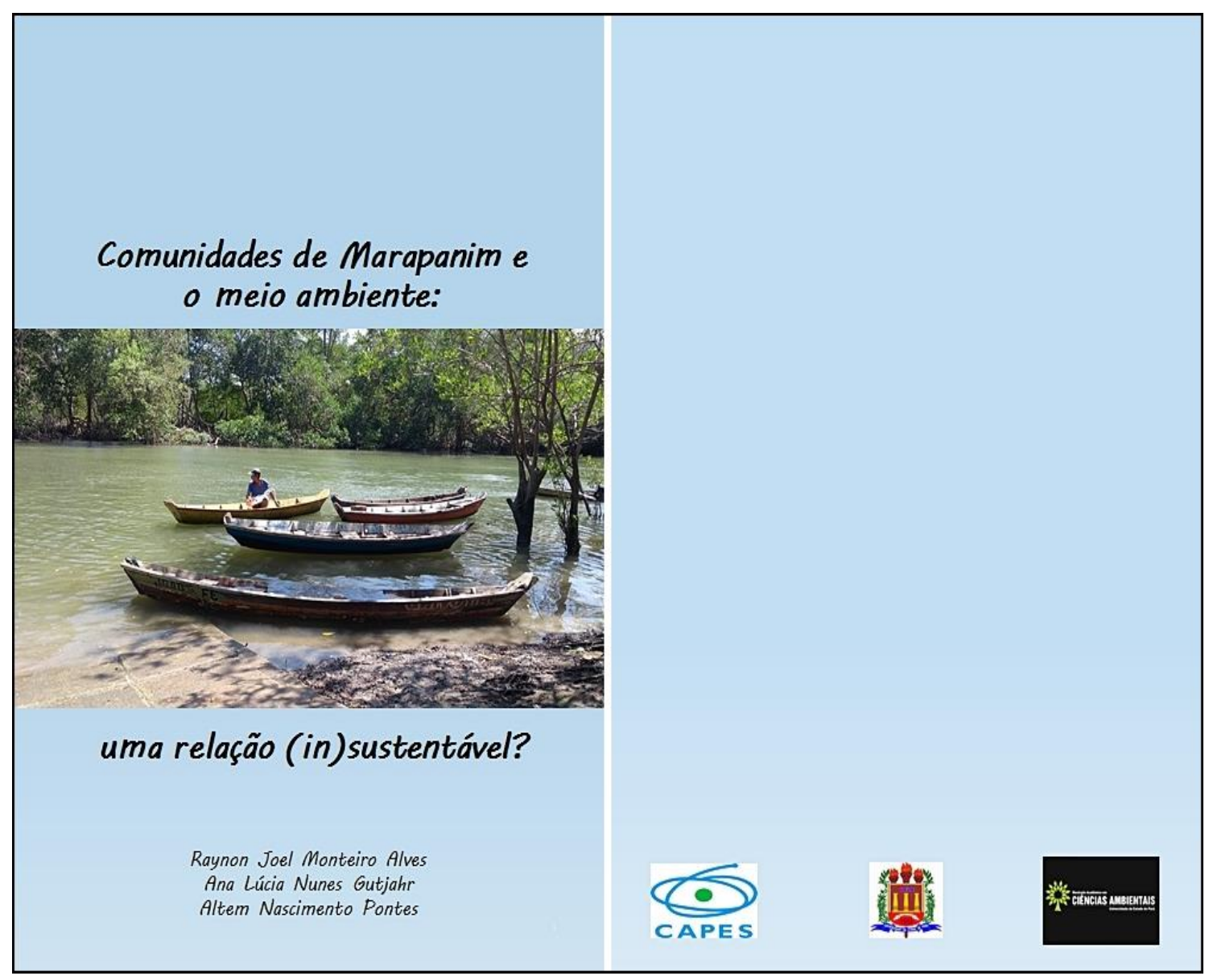

Figura 1: Páginas inicial e final referentes à capa e contracapa da cartilha "Comunidades de Marapanim e o meio ambiente: uma relação (in)sustentável?".

A cartilha apresenta, além da capa, outros elementos pré-textuais: a apresentação, que brevemente expõe a origem do material que será tratado, os objetivos e a didática utilizada para facilitar a compreensão dos leitores; e o sumário, que contém a paginação de cada tópico presente no corpo do manuscrito (Figura 2). 


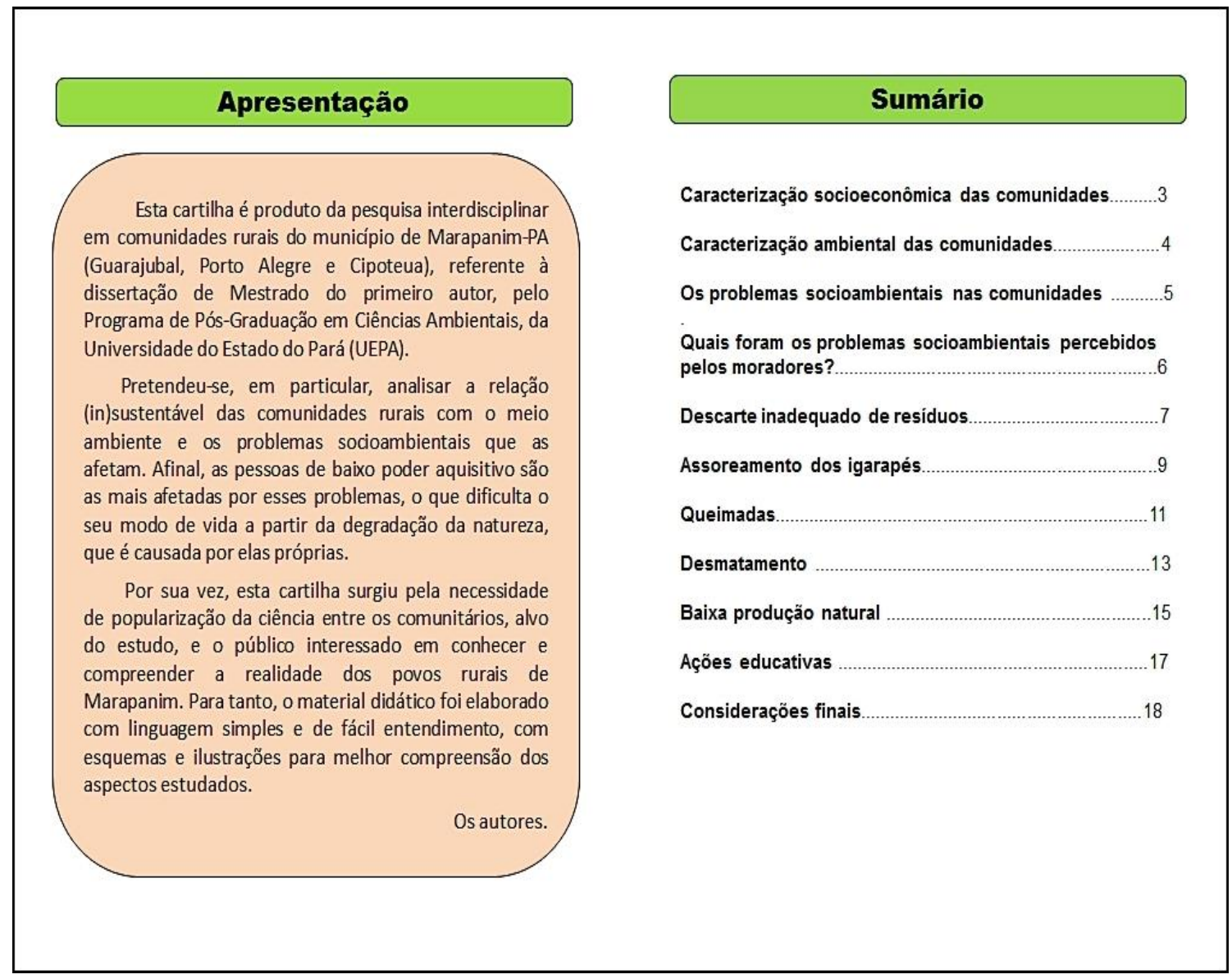

Figura 2: Páginas referentes à apresentação e ao sumário da referida cartilha.

Para uma apresentação didática dos conteúdos da cartilha, os elementos textuais foram estruturados em tópicos: (1) Caracterização socioeconômica e (2) Caracterização ambiental das comunidades; (3) Problemas socioambientais nas comunidades; (4) Os problemas socioambientais percebidos pelos moradores; (5) Descarte inadequado de resíduos; (6) Assoreamento dos igarapés; (7) Queimadas; (8) Desmatamento; (9) Baixa produção natural; (10) Ações educativas (11) Considerações finais e Agradecimentos. Ressalta-se que para cada um dos problemas socioambientais abordados foram propostas ações sustentáveis para mitigá-los ou preveni-los.

\section{(1) Caracterização socioeconômica das comunidades}

Neste tópico, a cartilha apresenta uma breve descrição das comunidades de Guarajubal, Porto Alegre e Cipoteua em relação ao perfil socioeconômico e laboral dos moradores locais e os principais fatores que desencadeiam problemas socioambientais e que, por sua vez, afetam a qualidade de vida humana nessas localidades. Mostra também um mosaico de 
imagens que representam aspectos desses povoados, seguidos de dados sobre a localização dos mesmos, o número de famílias residentes e as atividades agrícolas e/ou extrativistas de maior destaque desenvolvidas (Figura 3).

\section{(2) Caracterização ambiental das comunidades}

Este item caracteriza brevemente o aspecto ambiental dos três povoados estudados em relação às áreas naturais que formam os seus territórios e as categorias de importância do meio ambiente para essas populações rurais, com imagens das próprias comunidades para demonstrálas, além de informações sobre a gestão ambiental in loco (Figura 3).

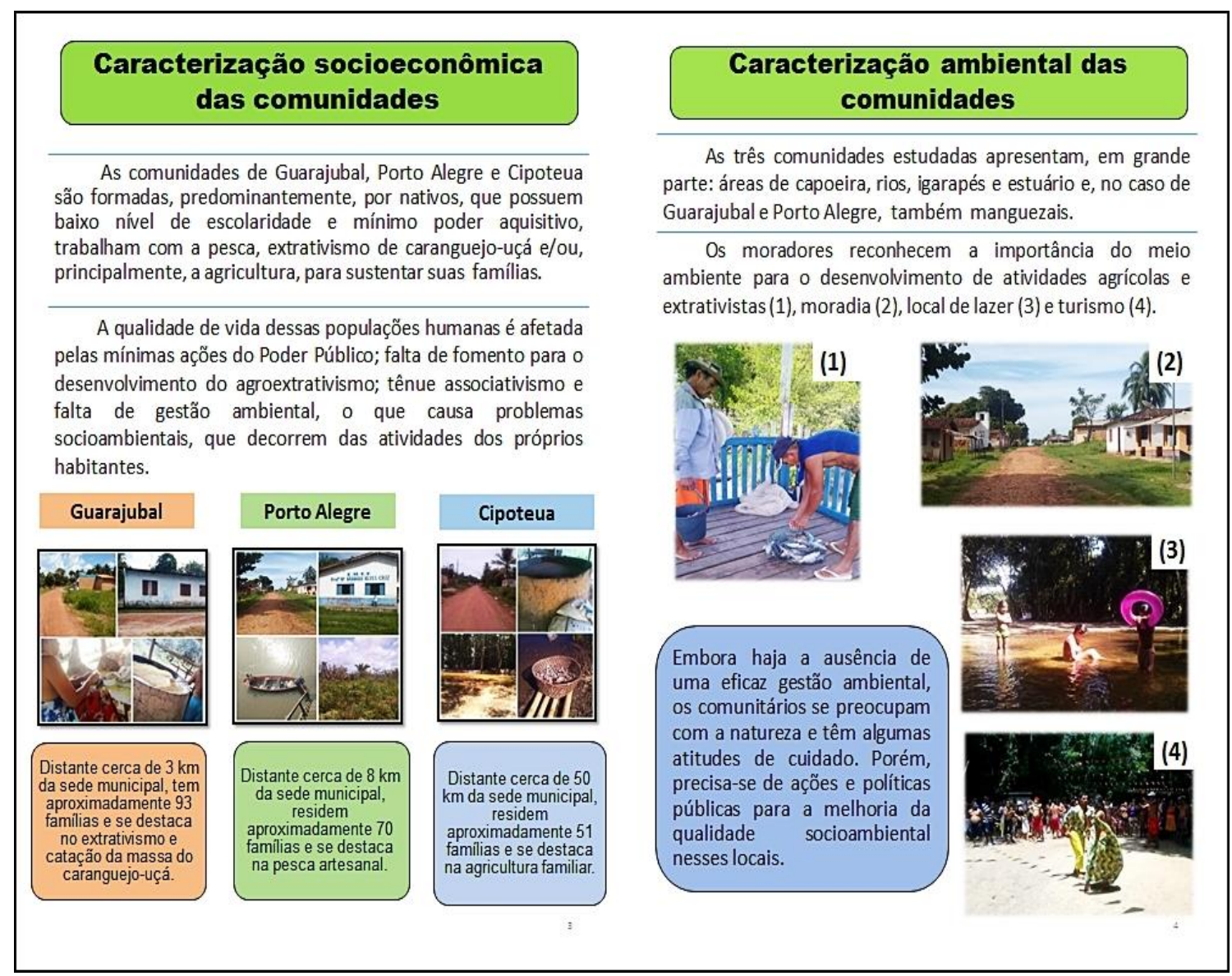

Figura 3: Páginas da cartilha referentes à caracterização socioeconômica e ambiental das comunidades estudadas.

\section{(3) Problemas socioambientais nas comunidades}

Nesta seção se faz uma breve conceituação sobre os problemas socioambientais em comunidades rurais e informa sobre como as condições socioeconômicas das pessoas, por meio de suas atividades cotidianas, influenciam negativamente o meio ambiente e vice-versa (Figura 4). 


\section{(4) Os problemas socioambientais percebidos pelos moradores}

Neste tópico foi apresentado, em ordem decrescente de citação pelos moradores, os cinco principais problemas socioambientais diagnosticados em Guarajubal, Porto Alegre e Cipoteua, assim como a descrição sucinta de cada um deles (Figura 4).

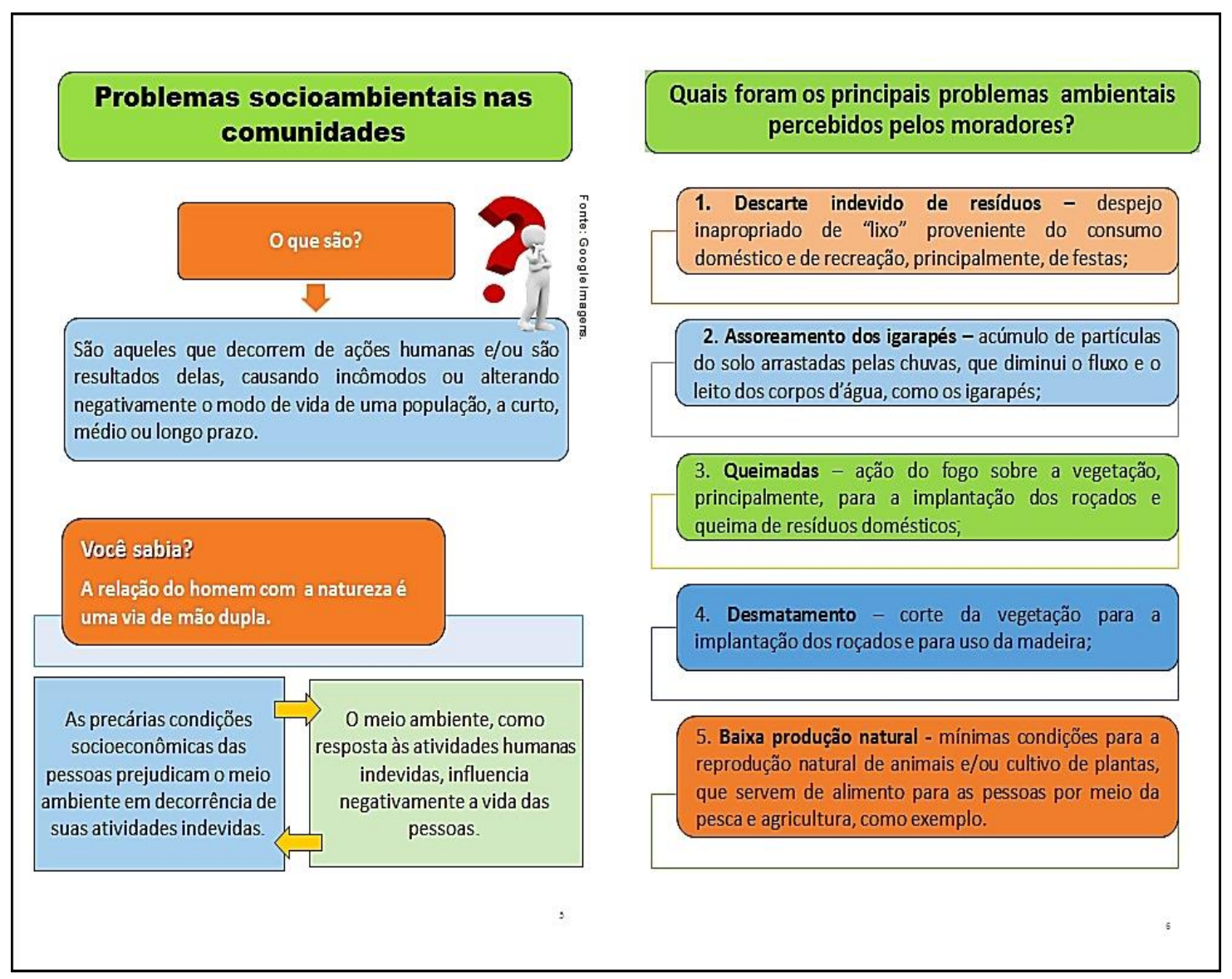

Figura 4: Páginas da cartilha referentes à conceituação de problemas socioambientais e os que foram diagnosticados nas três comunidades.

\section{(5) Descarte inadequado de resíduos}

Este item trata da disposição indevida de resíduos sólidos em ambientes terrestres e aquáticos nas três comunidades, discriminando a origem dos materiais pós-consumo e a diferença entre os conceitos de lixo e resíduos. Destaca também uma figura que representa o aspecto poluidor ambiental e visual, e as respectivas consequências decorrentes deste problema (Figura 5). Em resposta disso, sugerem-se três alternativas para o tratamento e o destino dos resíduos domésticos (secos e orgânicos), ilustrando-as e ressaltando a relevância socioeconômica e ambiental dessas ações, e a diferença entre os conceitos de reciclar e reutilizar (Figura 5). 


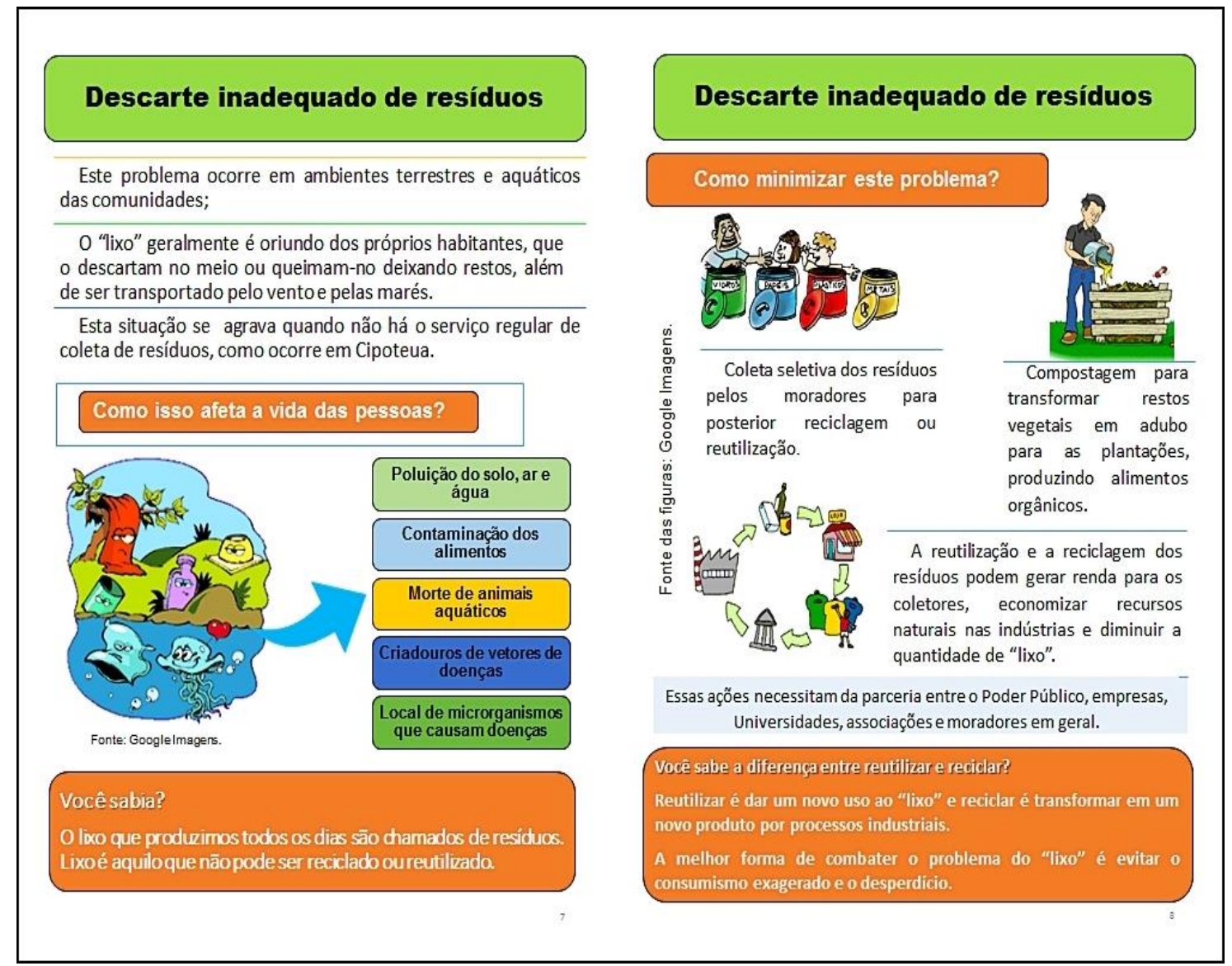

Figura 5: Páginas da cartilha referentes ao problema do descarte inadequado dos resíduos e suas respectivas alternativas mitigadoras.

\section{(6) Assoreamento dos igarapés}

Este tópico discorre sobre as principais causas para o assoreamento dos igarapés, isto é, quando os mesmos estão "secando" ou morrendo", de acordo com os comunitários das localidades estudadas. A seção também mostra o aspecto de um corpo hídrico assoreado e as implicações dele resultantes (Figura 6). Diante disso, foram propostas alternativas mitigadoras e preventivas relacionadas à conscientização e mobilização das pessoas, ilustrando-as e, em particular, demonstrando a importância da vegetação ripária, que, inclusive, é protegida pelo Código Florestal Brasileiro (Figura 6). 


\section{Assoreamento dos igarapés}

Este problema ocorre quando há o aterramento às margens de um igarapé, como em Cipoteua, e ruas sem asfalto e sem cobertura vegetal, como em Porto Alegre, permitindo que as enxurradas transportem partículas de solo para o interior dos cursos d'água.

A agricultura de corte e queima contribui com a diminuição dos recursos hídricos, pois há a supressão da vegetação próximo às nascentes (olhos d'água) e deixa o solo exposto à ação das chuvas.

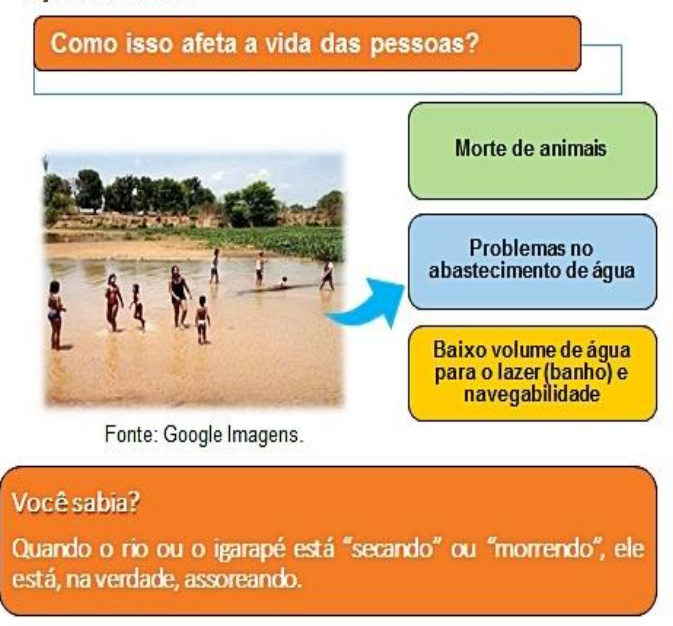

\section{Assoreamento dos igarapés}

Como minimizar este problema?

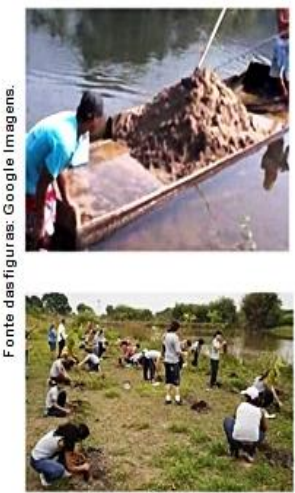

Evitar o aterramento de locais próximos aos corpos d'água; e, quando acontecer, retirar o excesso de aterro, individualmente ou por meio de mutirões comunitários, podendo ser usado em construções de alvenaria.

Proteger e/ou reflorestar com árvores nativas as matas no entorno dos igarapés e dos rios, que são chamadas de matas ripárias ou ciliares.

As matas ripárias ou ciliares são legalmente protegidas de acordo com o Código Florestal Brasileiro da Lei Federal no 12.651, de 2012.

\section{Vocésabia?}

As matas ripárias são aquelas que margeiam os corpos d'água sendo importantes para a manutenção da água, além de servir de proteção contra 0 desgaste do solo (erosão) e o assoreamento de rios e igarapés.

Figura 6: Páginas da cartilha referentes ao problema do assoreamento dos igarapés e as suas respectivas alternativas mitigadoras/preventivas.

\section{(7) Queimadas}

Nesta seção estão descritas informações sobre as queimadas, que são frequentes principalmente entre os agricultores familiares, como método de limpeza e preparo para os roçados; além disso, o fogo é utilizado para incinerar os resíduos sólidos. A cartilha aborda, ainda, as causas e os efeitos nocivos decorrentes da atividade, e uma imagem representa o aspecto destruidor das queimadas sobre a vegetação (Figura 7). Neste contexto, propõe-se a adoção de procedimentos de produção agrícola sem o uso do fogo, que deve ser viabilizado por órgãos de assistência técnica e de extensão rural ou por outras instituições competentes, e também incutir nas pessoas a responsabilidade em cuidar dos resíduos que produzem por meio de ações educativas (Figura 7). 


\section{Queimadas}

Esta prática decorre da agricultura tradicional e migratória, comumente conhecida como de corte-queima-pousio.

Este método é muito utilizado pelos agricultores para a implantação de roças, devido ao baixo custo e fácil uso, além da falta de políticas públicas e de assistência técnica para o financiamento da atividade e alternativas de produção.

0 fogo é também usado para eliminar resíduos domésticos, principalmente, em locais sem o serviço regular de coleta, como em Cipoteua.

\section{Como isso afeta a vida das pessoas?}
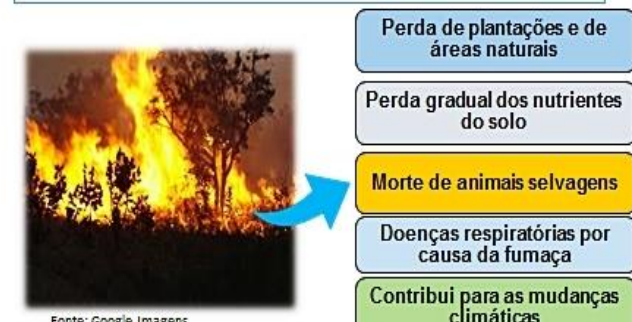
áreas naturais

Fonte: Google Imagens.

Perda gradual dos nutrientes do solo

Vocè sabia?

A queima das plantas libera nutrientes, presentes nas cinzas, que fertilizam o solo, mas esses nutrientes são levados pela chuva (lixiviação), deixando o solo infértil (pobre).

\section{Queimadas}

Como minimizar este problema?

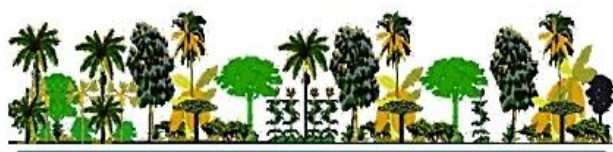

Métodos de implantação dos roçados sem o uso de fogo: a) corte e trituração da vegetação, deixando-a sobre o solo; b) sistemas agroflorestais (SAFs), que são consórcios de culturas agrícolas e árvores e/ou criação de animais.

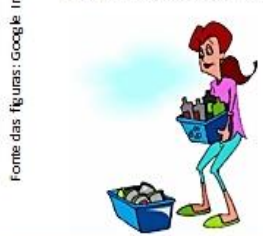

Iniciativa em coletar os resíduos para fins de reutilização e a reciclagem, além do consumo consciente.

Essas ações necessitam da parceria entre o Poder Público, Universidades, Embrapa, Emater, associações e moradores.

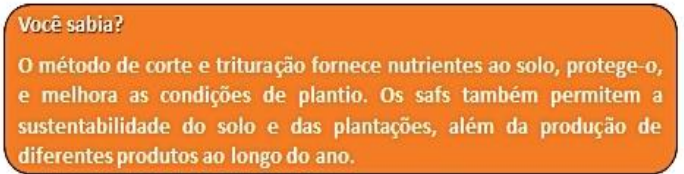

Figura 7: Páginas da cartilha referentes ao problema das queimadas e algumas alternativas mitigadoras.

\section{(8) Desmatamento}

Este item aborda a relação do desmatamento com a queimada, ambos para a implantação de roçados, e também trata sobre o uso de recursos madeireiros. Tem-se ainda uma ilustração referente ao efeito supressivo deste problema, seguida de alguns impactos socioambientais ocasionados por tais atividades, com ênfase na desertificação (Figura 8). Neste cenário, sugerem-se ações para a manutenção da vegetação, conservando-a, preservando-a e cultivando-a por meio de Sistemas Agroflorestais (SAF's), por exemplo (Figura 8). 


\section{Desmatamento}

Esta prática ocorre principalmente na agricultura tradicional, pois o corte e queima são complementares para a limpeza das áreas, sobretudo, de capoeiras (vegetação secundária).

Em menores frequências, está relacionado ao uso de recursos madeireiros para a confecção de instrumentos pesqueiros, domiciliares e combustíveis.

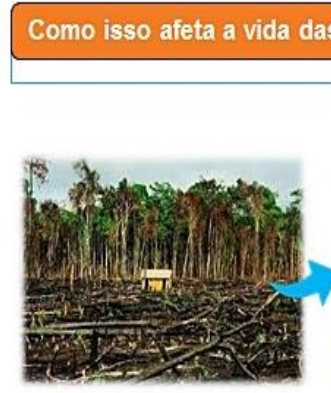

Fonte: Google Imagens.

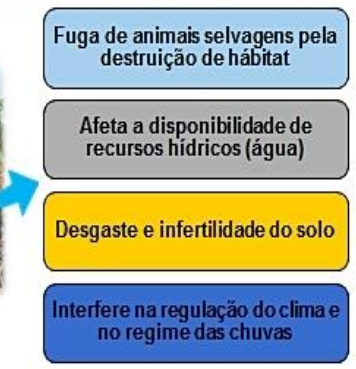

Vooêsabibia?

O desmatamento em deteminada área pode provocar o processo de desertificacajo, isto é, a formaça de desertos e regibos áridas

\section{Desmatamento}

Como minimizar este problema?

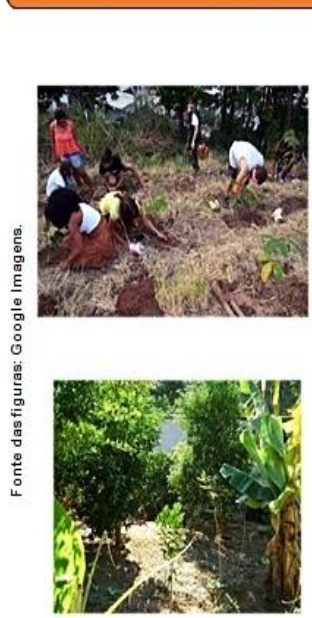

Além dos métodos alternativos de produção agrícola, já apresentados, a recuperação de áreas degradadas por reflorestamento de árvores nativas, e, se for o caso, por meio de Safs, e também a manutenção de matas ripárias.

Cultivo e manutenção de plantas frutíferas nos quintais, assim como vem ocorrendo em muitos quintais das comunidades. Estes quintais, em geral, fazem fronteira com a mata.

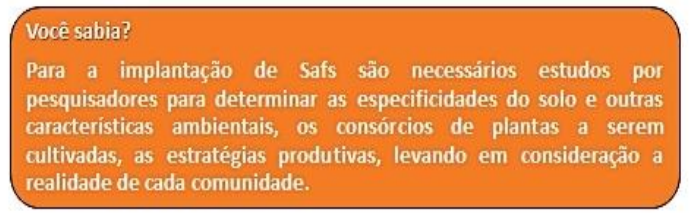

Figura 8: Páginas da cartilha referentes ao desmatamento e algumas alternativas mitigadoras/preventivas para tal problema.

\section{(9) Baixa produção natural}

Nesta seção da cartilha é caracterizada a baixa produção natural no território (manguezal, estuário, solo) das comunidades, destacando este problema como um impacto que decorre das atividades anteriormente mencionadas. Este tópico apresenta uma imagem que retrata a escassez de peixes para os pescadores artesanais e cita outras consequências, além de expor a importância de órgãos públicos de fiscalização do meio ambiente (Figura 9). São também apresentadas as ações mitigadoras e preventivas que estão baseadas na conscientização e na participação das populações locais, visando a sustentabilidade da biodiversidade e dos trabalhadores agrícolas e extrativistas (Figura 9). 


\section{Baixa produção natural}

Este problema foi o menos percebido pelos comunitários, mas se caracterizou pela pequena quantidade de caranguejos nos manguezais de Guarajubal; escassez de peixes no rio, em Porto Alegre; e na infertilidade do solo para o plantio, nas três comunidades.

Este é um impacto ambiental que decorre das atividades humanas anteriormente mencionadas, que, se não forem controladas, tendem a piorar a situação.

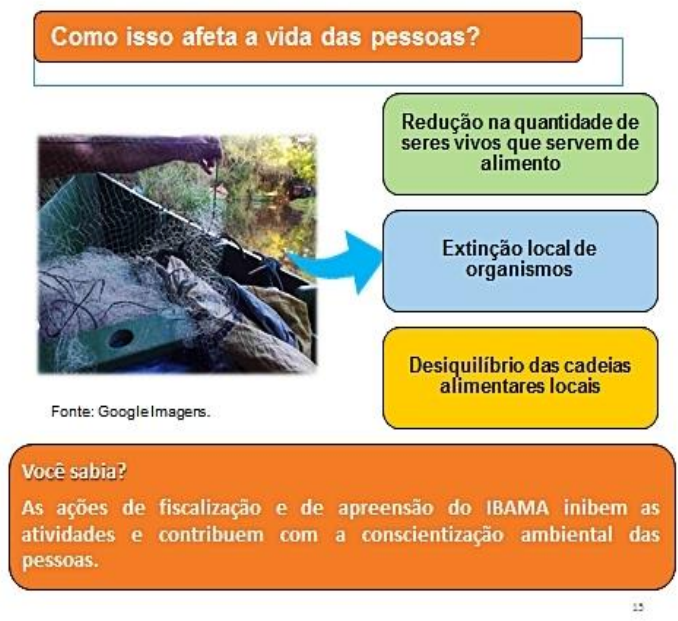

\section{Baixa produção natural}

Como minimizar este problema?

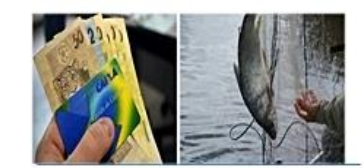

Através de ação pública para possibilitar o Seguro Defeso aos pescadores e extrativistas de caranguejo, além de respeito ao período de reprodução das espécies.

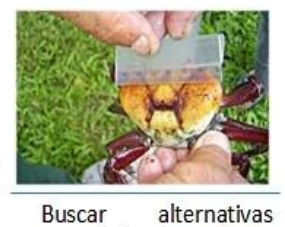
sustentáveis de produção agrícola e de uso consciente dos recursos extrativos.

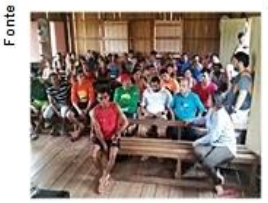

Participação na elaboração de um plano de manejo, por instituiç̃os de pesquisa, adequado à realidade de cada comunidade, considerando também o conhecimento dos trabalhadores agroextrativistas.

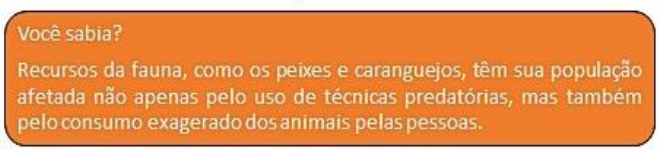

Figura 9: Páginas da cartilha referentes ao problema da baixa produção natural e a sugestão de alternativas para minimizá-lo/preveni-lo.

\section{(10) Ações educativas}

Este tópico, em particular, discorre sobre as ações educativas que podem contribuir com a sustentabilidade da relação sociedade versus natureza, sugerindo a Educação Ambiental como metodologia para as diversas atividades que visam a mudança de mentalidades e atitudes, em prol do meio ambiente e do bem comum (Figura 10). Ressalta também as contribuições dessas ações para a melhor qualidade de vida dos moradores de Guarajubal, Porto Alegre e Cipoteua, assim como os de outras comunidades.

\section{(11) Considerações finais e Agradecimentos}

Nesta seção da cartilha são tecidas considerações sobre o estudo realizado nas comunidades de Guarajubal, Porto Alegre e Cipoteua, evidenciando as inúmeras e principais formas de uso e apropriação do território e dos recursos naturais; e os problemas socioambientais que acometem a relação homem-natureza nestes povoados, cuja realidade é similar entre as demais comunidades do município de Marapanim. 
Destaca ainda a necessidade de parcerias entre o Poder Público, as Instituições de Ensino/Pesquisa/Extensão e os moradores locais para a efetivação das ações sustentáveis propostas, assim como a importância da Educação Ambiental como ferramenta para tais ações (Figura 10). Por último, tem-se o agradecimento à Coordenação de Aperfeiçoamento de Pessoal de Nível Superior (CAPES), na condição de agência financiadora do estudo socioeconômico e ambiental realizado nas três comunidades supracitadas (Figura 10).

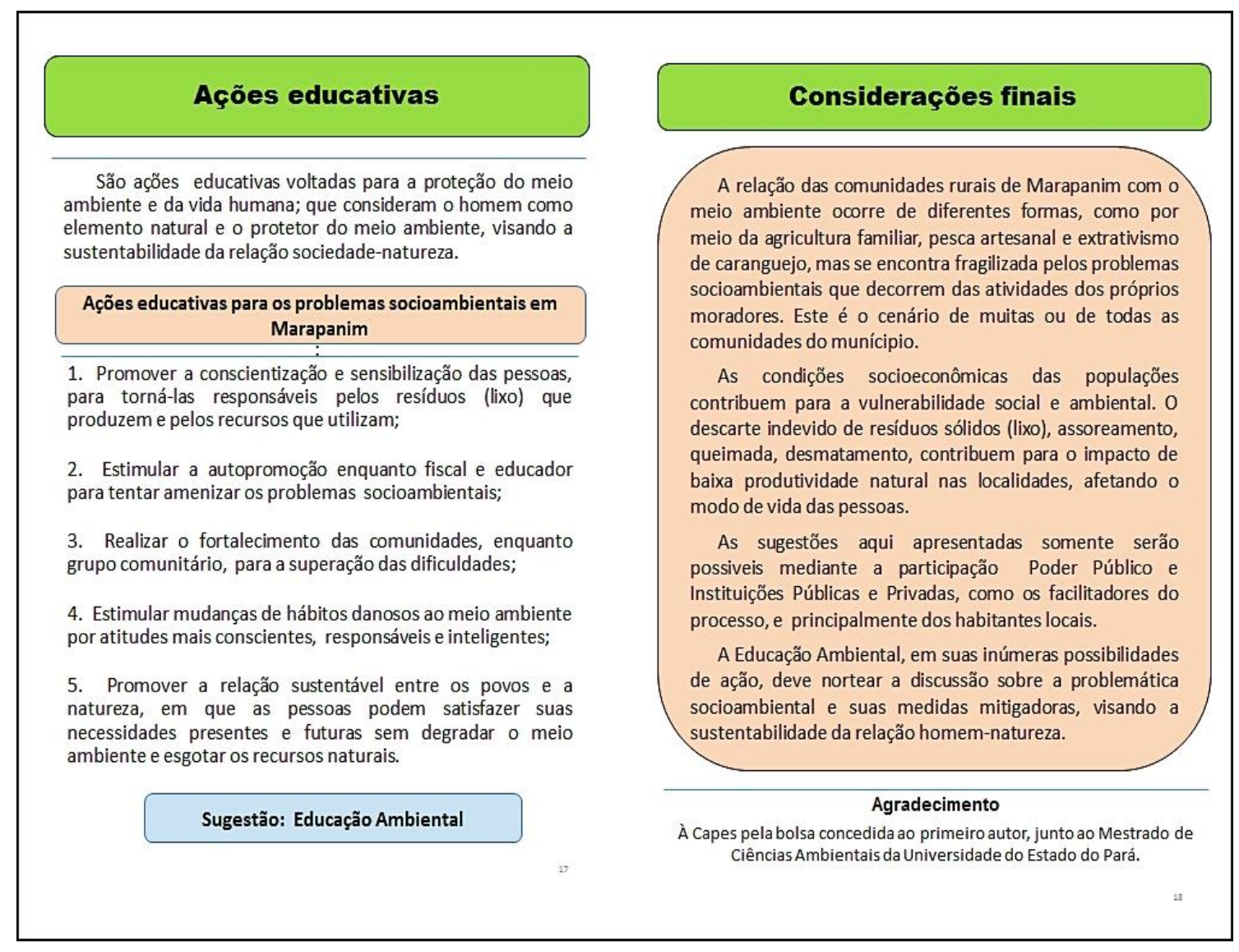

Figura 10: Páginas da cartilha referentes às ações educativas e, posteriormente, as considerações finais sobre o trabalho e agradecimento.

Esta cartilha, como material paradidático, foi elaborada didaticamente com linguagem de fácil compreensão para pessoas das comunidades em geral, sem nenhuma restrição. Visando o melhor entendimento do eleitor, ela possui ilustrações e curiosidades para estimular a leitura, o aprendizado e a percepção dos leitores em relação aos problemas abordados e suas possíveis ações de intervenção e prevenção.

Como o objetivo da referida cartilha é atender ao público infantil, juvenil e adulto, de diferentes faixas etárias e grau de instrução, torna-se necessário deixá-la atrativa aos olhares do leitor, bem como facilitar a interpretação de seu 
conteúdo. É neste sentido que se destaca, de acordo com Malcher, Costa e Lopes (2013), a necessidade de adaptar a linguagem no processo de aproximação do conteúdo científico a diferentes públicos.

Sobre as cartilhas, vale ressaltar que é característico nesse tipo de material educativo a presença de recursos visuais, como: desenhos, caricaturas ou fotografias, layout colorido e formatação tipográfica especial (MARTEIS; MAKOWSKI; SANTOS, 2011). Estes autores ainda aprovam a presença de seções denominadas "curiosidades", como as propostas nas condições de perguntas como "Você sabia?". Esta importância se dá ao fato de que podem existir informações que não são de domínio público e que, em geral, são eficazes para atrair a atenção dos leitores, pois dificilmente não serão lidas, ao contrário de outras partes do material que não apresentam nenhum tipo de destaque.

A produção de cartilhas com ênfase em problemas socioambientais em comunidades rurais visa informar e sensibilizar a população sobre o assunto e propor alternativas sustentáveis e viáveis para minimizá-los ou preveni-los, além de caracterizar o papel de extensão das Instituições de Ensino Superior, como é o caso da Universidade do Estado do Pará. Entre as possibilidades de aplicação desta cartilha, citam-se:

(1) Em instituições de Ensino Básico do meio urbano e principalmente rural, a fim de contemplar o público estudantil, em geral, sobre os problemas socioambientais (causas e medidas mitigadoras/preventivas), contribuindo com o empoderamento do alunato como a geração responsável pelo cuidado com o meio ambiente e, consequentemente, da vida humana em sociedade. Pode ser utilizado como subsídio ao se tratar de um tema transversal, em atividades de Educação Ambiental e em projetos educativos das escolas.

(2) Em meio eletrônico, podendo servir de base para estudos similares, visando a popularização dos resultados de trabalhos de conclusão de curso, dissertações e teses, e também como subsídio para a preparação de palestras, ações socioambientais, projetos, entre outros.

(3) Em audiências públicas nas comunidades rurais de Marapanim para a reformulação do Plano Diretor Participativo do município - este caso em particular se refere ao escopo ambiental do documento supramencionado, o qual está atualmente em processo de atualização e, para isso, encontros serão realizados com os moradores da zona rural. Nestas condições, as informações da cartilha podem contribuir para a melhoria da qualidade ambiental e das condições de vida das pessoas, principalmente por meio de suas próprias ações, mas com o auxílio do Poder Público. 
(4) Em ações interdisciplinares de órgãos públicos vinculados à Prefeitura, como: as Secretarias de Meio Ambiente, de Agricultura, de Pesca e Aquicultura, visando a promoção de medidas de educação e intervenção in loco, como atividades de Educação Ambiental, assim como 0 auxílio para a execução das possíveis medidas mitigadoras/preventivas contra os problemas socioambientais presentes na cartilha.

Diante do exposto, defende-se a ideia de que a Ciência, fazendo jus a sua natureza, tem que ser aberta, comunicada não apenas à comunidade científica, mas, sobretudo, de diferentes formas à sociedade em geral, começando pela escola (SILVEIRA; ATAÍDE; FREIRE, 2009), e, para isso, é importante desenvolver materiais e suportes acessíveis a todos (CAMARGO, 2015). Dentre os mecanismos de divulgação ou de Popularização da Ciência, citam-se como exemplos: histórias em quadrinhos sobre saúde pública (MENDONÇA, 2008); cartilha educativa sobre mimercofauna (RABELO; GUTJAHR; HARADA, 2015); teatro de cunho científico em centro universitário (SILVEIRA; ATAÍDE; FREIRE, 2009), distintas categorias de artes cênicas em museus e centros de ciências do Brasil (MOREIRA; MARANDINO, 2015) e exposições da biodiversidade amazônica em praças públicas (GUTJAHR et al., 2015).

Atenção especial deve ser dada à importância dos estabelecimentos de ensino em razão da representatividade que estes possuem na sociedade, pois neles estão presentes membros da maioria das famílias das comunidades (REGIS et al., 1996). Com uma cartilha, por exemplo, pode-se aproximar a escola de um problema vigente, integrá-lo ao conteúdo programático e trabalhá-lo com crianças e adolescentes, visto que estes são mais fáceis de mudar de atitude que os adultos (lbidem), característica que deve ser imprescindível ao se tratar de ações de EA. Afinal, esses estudantes ambientalmente conscientizados são potenciais agentes disseminadores das informações assimiladas entre os familiares, amigos e vizinhos, rompendo os limites das instituições de ensino, por meio de atividades extraescolares planejadas ou nas situações informais do dia-a-dia.

Outro aspecto a ser considerado em relação às cartilhas se refere ao incremento no acervo científico e bibliográfico de determinada região a partir de estudos interdisciplinares in loco, cujos resultados podem ser amplamente difundidos em eventos, internet e meios de comunicação, fortalecendo também o processo de Popularização da Ciência. Tais subsídios não só permitem o reconhecimento da realidade pelos moradores, mas também o conhecimento da mesma por outras pessoas, como as das secretarias do Poder Público Municipal, a fim de que possam atuar no local de diferentes formas, visando o bem-estar socioambiental das populações humanas, que, por sua vez, devem também fazer parte deste processo em prol do bem comum. 


\section{Conclusão}

As cartilhas educativas podem ser importantes mecanismos de Popularização da Ciência, quando atrativas e elaboradas de forma acessível a diferentes públicos-alvo. Para isso, são necessários o conhecimento da realidade ou do assunto a ser abordado, embasamento teórico, criatividade ao elaborar o material paradidático e estratégias de difusão das informações, a fim de atingir um maior número de pessoas leigas e interessadas na temática, como: professores, estudantes, comunitários, servidores públicos, representantes do Poder Público, entre outros.

A referida cartilha, diante de suas possíveis aplicações, poderá não apenas aproximar a sociedade dos conhecimentos científicos adquiridos com a pesquisa das comunidades rurais de Guarajubal, Porto Alegre e Cipoteua, mas também sensibilizá-la sobre a problemática socioambiental nesses povoados, evidenciando que as pessoas (leigas) podem intervir em sua realidade, de forma sustentável, como por meio de algumas sugestões apresentadas na cartilha em questão. Em particular, dá-se importância à Educação Ambiental e sua implementação em espaços formais e não formais de ensino, possibilitando a formação de agentes multiplicadores de informações e conscientemente atuantes no local onde (con)vivem.

\section{Agradecimentos}

À Coordenação de Aperfeiçoamento de Pessoal de Nível Superior (CAPES) pelo apoio financeiro à pesquisa.

\section{Referências}

BACELAR, B. M. F.; PINHEIRO, T. S. M.; LEAL, M. F.; PAZ, Y. M.; LIMA, A. S. T.; ALBUQUERQUE, C. G.; EL-DEIR, S. Metodologia para elaboração de cartilhas em projetos de educação ambiental em micro e pequenas empresas. Recife (PE): Jepex. 2009.

BRASIL. Lei no 9.795, de 27 de abril de 1999. Dispõe sobre a educação ambiental, institui a Política Nacional da Educação Ambiental e dá outras providências. Brasília, Diário Oficial, 27 de abril de 1999. Disponível em: http://www.planalto.gov.br/ccivil 03/LEIS/L9795.htm. Acesso em: 10 jan. 2018.

BUENO, W. C. Comunicação científica e divulgação científica: aproximações e rupturas conceituais. Informação \& Informação, Londrina, v. 15, p. 1 - 12, 2010.

CAMARGO, V. R. T. Dialogando com a ciência: ações, atuações e perspectivas na divulgação científica e cultural. C\&S, São Bernardo do Campo, v. 37, n. 3, p. 43-71, 2015. 
GUTJAHR, A. L. N.; BRAGA, C. E. S. B.; RESQUE-JÚNIOR, B. T. B.; RABELO, R. C. Ação de popularização da ciência realizada em praças públicas do município de Belém, Pará, Brasil. Enciclopédia Biosfera, Goiânia, v.11 n. 21; p. 2803-2814, 2015.

MALCHER, M. A.; COSTA, L. M.; LOPES, S. C. Comunicação da Ciência: diversas concepções de uma mesma complexidade. Animus - Revista Interamericana de Comunicação Midiática, v. 12, n. 23, p. 59-84, 2013.

MARTEIS, L. S.; MAKOWSKI. L. S.; SANTOS, R. L. C. Abordagem sobre Dengue na educação básica em Sergipe: análise de cartilhas educativas. Scientia Plena, v. 7, n. 6, p. 1-8, 2011.

MENDONÇA, M. R. S. Ciência em quadrinhos: recurso didático em cartilhas educativas. Tese (Doutorado em Letras). Universidade Federal de Pernambuco. Recife, 2008. $223 f$.

MOREIRA, L. M.; MARANDINO, M. O teatro em museus e centros de ciências no Brasil. História, Ciências, Saúde - Manguinhos, Rio de Janeiro, v. 22, p.1735-1748, 2015.

NUNES, A. R. S.; SILVA, M. L.; ARAÚJO, M. L. Educação ambiental portuária: trajetórias educativas da companhia docas do Pará (terminal petroquímico de Miramar) em Belém/ PA. Revista Eletrônica do Mestrado em Educação Ambiental, v. especial, p. 80-92, 2013.

RABELO, R. C.; GUTJAHR, A. L. N.; HARADA, A. Y. Metodologia do processo de elaboração da cartilha educativa "O papel das formigas na natureza". Enciclopédia Biosfera, Goiânia, v.11 n. 21; p. 2769-2777, 2015.

REGIS, L.; FURTADO, A. F.; OLIVEIRA, C. M. F.; BEZERRA, C. B.; SILVA, L. R. F.; ARAÚJO, J.; MACIEL, A.; SILVA-FILHA, M. H.; SILVA, S. B. Controle integrado do vetor da filariose com participação comunitária, em uma área urbana do Recife, Brasil. Cadernos de Saúde Pública, Rio de Janeiro, v. 12, n. 4, p. 473-482, 1996.

SILVEIRA, A. F.; ATAÍDE, A. R. P.; FREIRE, M. L. F. Atividades lúdicas no ensino de ciências: uma adaptação metodológica através do teatro para comunicar a ciência a todos. Educar, Curitiba, n. 34, p. 251-262, 2009. 